\title{
Abscisic Acid Synthesis in Acer rubrum L. Leaves- A Vapor-pressure-deficit-mediated Response
}

\author{
W.L. Bauerle ${ }^{1}$ \\ Department of Horticulture, Clemson University, Clemson, SC 29634 \\ T.H. Whitlow \\ Department of Horticulture, Cornell University, Ithaca, NY 14853 \\ T.L. Setter \\ Department of Crop and Soil Science, Cornell University, Ithaca, NY 14853 \\ F.M. Vermeylen \\ Office of Statistical Consulting, Cornell University, Ithaca, NY 14853
}

\begin{abstract}
AdDitional INDEX WORDS. vapor pressure deficit, ecotypic variation, red maple, abscisic acid
ABstract. Quantitative differences in leaf abscisic acid (ABA) among Acer rubrum L. (red maple) ecotypes were investigated. This study tested the hypothesis that seedlings from wet and dry maternal sites display distinctly different capacities to synthesize $A B A$ in response to atmospheric vapor pressure deficits. The increased levels of $A B A$ in leaf tissue in the red maple ecotypes were associated with atmospheric vapor pressure deficit (VPD). Leaves on well-watered plants responded to VPD by increasing their ABA levels and reducing their photosynthesis $\left(\mathrm{A}_{\text {net }}\right)$ and stomatal conductance $\left(g_{s}\right)$. Both ecotypes appear to accumulate ABA at about the same rate as VPD increased. Despite the similar accumulation rates between ecotypes, wet site ecotypes consistently had a higher level of ABA present in leaf tissue under both low and high VPD conditions. Furthermore, wet site provenances appear to reduce $A_{\text {net }}$ and $g_{s}$ in response to $A B A$ accumulation, whereas dry sites do not present as clear an $\mathrm{ABA} / \mathrm{g}_{\mathrm{s}}$ relationship. This study shows variation between wet and dry site red maple populations in physiological response to atmospheric vapor pressure deficits, indicating that natural ecotypic variation in stomatal responsiveness to air humidity is likely mediated by ABA accumulation in leaf tissue. This research demonstrates that ecotypes of red maple may be selected for atmospheric drought tolerance based on site moisture conditions.
\end{abstract}

Stomata are the primary passageway for $\mathrm{CO}_{2}$ diffusion into the substomatal cavity and allow the plant to regulate water loss and carbon gain. Recent evidence suggests that stomatal conductance $\left(\mathrm{g}_{\mathrm{s}}\right)$ correlates better with environmental variables such as air temperature, vapor pressure deficit (VPD), and photosynthetic photon flux density (PPFD) than with plant variables such as shoot water potential, turgor potential, bulk leaf osmotic potential, xylem $\mathrm{pH}$, and xylem sap abscisic acid (Augé et al., 2000). Plants are known to respond to a high leaf-to-air VPD by closing their stomata (Maroco et al., 1997; Meinzer et al., 1997; Thomas and Eamus 1999) and this response has been observed in a variety of species (Monteith, 1995; Sheriff, 1979). Studies of well-watered Douglas-fir and alder roots indicate that the declines in leaf water potential associated with transpiration-induced water potential decline can induce stomatal closure without invoking a change in soil water potential (Fuchs and Livingston, 1996). Gollan et al. (1986) maintained the same leaf water potentials across the soil-plant-water continuum as the soil dried, so the closure of stomata occurred in drying soil despite the same demand/supply regime.

Abscisic acid (ABA) has been shown to be a stress signal that permits communication between the roots and shoots, especially when the root system is under stress (Davies and Zhang, 1991;

Received for publication 1 May 2003. Accepted for publication 10 Oct. 2003. The authors thank A. Lakso, and S. Maki for helpful discussions of earlier drafts of this manuscript, A. Leed for technical assistance and M. Compton and A. Roberts for plant care. We also thank Nursery Supply, Inc. for donating the pots. This work was supported by USDA Hatch Projects NYC-141370 and NYC-141406.

'Corresponding author; e-mail bauerle@clemson.edu.
Davies et al., 1994). The hypothesis that ABA is the only root signaling molecule, however, has been challenged (Munns, 1992; Munns and King, 1988; Munns et al., 1993; Trejo and Davies 1991). Currently, there is a paucity of studies that investigate the effect of atmospheric water deficit on the production of ABA. Gollan et al. (1986) and Turner et al. (1985) carefully unscrambled the effect of VPD and soil drying on photosynthesis and conductance that led to the subsequent work on root-shoot signals and ABA. Augé et al. (2000) found that VPD better described stomata sensitivity to ABA than shoot water potential $\left(\Psi_{w}\right)$. Nonetheless, a nonhydraulic chemical factor that permits plants to sense and respond to soil drying seems to exist (Davies and Zhang, 1991; Davies et al., 1994; Liang et al., 1996; Loewenstein and Pallardy, 1998a, 1998b; Zhang et al., 1987).

Acer rubrum L. (red maple) is one of the most widespread hardwood tree species in North America (Walters and Yawney, 1990). Not only does red maple have a wide range, it thrives under a wider variety of site/soil conditions than most other North American tree species. With respect to horticulture, it is a popular ornamental tree and is commonly placed on a variety of landscapes. Subsequent studies indicate that red maple populations are genetically variable for traits including drought tolerance of substrate moisture (Abrams and Kubiske, 1990; Bauerle et al., 2003a, 2003b; Townsend and Roberts, 1973); however, a review of the literature reveals no investigations of atmospheric stress tolerance.

The goal of the study was to examine the range of stomatal control displayed by red maple trees grown under well-watered conditions when subjected to extreme atmospheric VPD. The 
horticultural popularity and natural variation within the species warrants red maple as a good model for this study. Red maple populations originating from water-limiting sites (dry site) osmotically adjust and have a lower capacity for growth when compared to sites were water is not limiting (wet site) (Bauerle et al., 2003b). The dry-site seedlings appear to have tissue better adapted to withstand dehydration and might be less sensitive to nonhydraulic signaling because they can osmotically adjust. Conversely, red maple populations originating from sites where water is not limiting do not osmotically adjust. We hypothesize that wet-site trees may have a greater ability to both biosynthesize and catabolize ABA, a nonhydraulic root-to-shoot signal, to control excess transpirational water loss during periods of excess atmospheric water demand. The altered stomatal control would constitute a sensitive mechanism by which transpiration is reduced in an ecotype that does not normally experience water deficits and aid in selection strategies for atmospherically stressful landscape situations (e.g., urban heat islands).

In this study, we address the following questions: 1) Does the ABA stress response quantitatively differ among red maple ecotypes, 2) What is the relative importance of leaves as sensors of atmospheric water deficits in red maple, and 3) Does red maple show ecotypic differences in leaf synthesis of ABA? Specifically, this study examined physiological mechanisms of drought tolerance in red maple seedlings from eight provenances. Six provenances represented the wet and dry hydrologic extremes in New York. The other two sites, both in Virginia, represented among the wettest and driest sites inhabited by red maples in North America. Altogether then, trees from four wet and four dry sites were subjected to stress by creating atmospheric water deficits and then relieving the water stress.

\section{Materials and Methods}

Plant materials. The geographic origin, site descriptions, and seedling establishment have been described elsewhere, Bauerle et al. (2003b). Specific to this experiment, 144 seedlings comprised 18 replications from each of the four wet and four dry sites. Annual cohort 1998 plant material was randomly selected from the eight sites in May 2000. Briefly, a wet site was defined by poorly drained soils that are saturated in the spring during seed development (a wetland or swamp), and a dry site was defined by well-drained upland soils.

Growth CHAMBER CONDITIONS. Two walk-in growth chambers (Environmental Growth Chamber Co., Chagrin Falls, Ohio) were used to control light and temperature. Within the control room $\left(\mathrm{C}_{1}\right)$, an ambient whole plant chamber $\left(\mathrm{VPD}_{\mathrm{A}}\right)$, dimensions 1 $\times 1 \times 0.66 \mathrm{~m}^{3}$, was constructed from polyvinyl chloride (PVC) tubing covered with clear $2 \mathrm{~mm}$ Mylar. A data logger monitored relative humidity (model Hobo Pro; Onset Computer Corp., Pocasset, Mass.) and an infrared thermocouple (OS36, Omega Co., Stamford, Conn.), connected to a remote datalogger (CR21X; Campbell Scientific Inc., Logan, Utah), monitored temperature inside each individual chamber at minute intervals.

Within the treatment room $\left(\mathrm{C}_{2}\right)$, two Mylar chambers were constructed, identical to the chamber in $\mathrm{C}_{1}$. During VPD stress, moisture was removed from the ambient atmospheric air via a cold plate condenser and Drierite desiccant and the temperature was set at $34^{\circ} \mathrm{C}$, high vapor-pressure-deficit chamber $\left(\mathrm{VPD}_{\mathrm{H}}\right)$. A plenum heated with three $150-\mathrm{W}$ incandescent lights brought the temperature back to $34^{\circ} \mathrm{C}$ before entering the dehumidified chamber. In addition, $7.25 \mathrm{~kg}$ of Drierite was spread over the bot- tom of the $\mathrm{VPD}_{\mathrm{H}}$ to aid in further removal of $\mathrm{H}_{2} \mathrm{O}$. In the second Mylar chamber, water was added to the ambient atmospheric air stream via three ultrasonic humidifiers (Sunbeam Inc., BocaRaton, Fla.). Again, air was passed through a plenum to bring the temperature back up to $34^{\circ} \mathrm{C}$ before entering the humidified chamber $\left(\mathrm{VPD}_{\mathrm{w}}\right)$.

Each Mylar chamber held 3 maple tree seedlings at any given time. Environmental parameters were varied over a $12 \mathrm{~h}$ time course for each of the eight red maple ecotypes, which resulted in one ecotype per day being processed. The containers of the seedlings were sealed in white plastic bags to prevent evaporation. The treatments started at $0800 \mathrm{HR}$. Leaf gas exchange and ABA were measured to indicate the impact of ambient, atmospheric VPD and humidified elevated temperature conditions, as well as post stress responses. Leaf disks were harvested every $4 \mathrm{~h}$ on all plants within the chambers (five $1 \mathrm{~cm}$ disks per tree) and gas exchange data collected every $2 \mathrm{~h}$ from a subsample of plants (one per chamber) with a gas analyzer (LI-6400; LI-COR, Inc., Lincoln, Neb.). The gas exchange chamber was placed inside the growth chamber for a period of no less than $0.5 \mathrm{~h}$ to equilibrate with growth chamber conditions before the beginning of a measurement. At $1600 \mathrm{HR}$ (hour 8) the $\mathrm{VPD}_{\mathrm{H}}$ and $\mathrm{VPD}_{\mathrm{W}}$ chambers were returned to ambient relative humidity until $2000 \mathrm{~h}$ in order to investigate the decline in ABA in the leaf tissue during the 4-h poststress time frame.

ABA SAMPLING. Using a 1-cm cork borer, leaf disks were collected from the first through third fully expanded leaves every 4 h. The protocols were simple modifications of Alves and Setter (2000). Briefly, five 1-cm-diameter leaf disks were harvested from each replicated seedling and immediately placed in a precooled $\left(0^{\circ} \mathrm{C}\right) 1.5-\mathrm{mL}$ microcentrifuge tube containing $676 \mu \mathrm{L}$ of extraction medium ( $80 \%$ v/v methanol, $20 \%$ v/v glass distilled $\mathrm{H}_{2} \mathrm{O}$ ). Samples were stored at $-18^{\circ} \mathrm{C}$ until analysis. A $200 \mu \mathrm{L}$ extract per sample was lyophilized and then redissolved in $150 \mu \mathrm{L}$ of aqueous $+1 \% \mathrm{v} / \mathrm{v}$ glacial acetic acid and $10 \mu \mathrm{L}$ of $\left[{ }^{3} \mathrm{H}\right] \mathrm{ABA}$ with sonication. Chromatography columns were constructed with micropipette tips containing $0.15 \mathrm{~g}$ of silica $\mathrm{C}_{18}$ packing material (40 $\mu$ m particle size). Columns were washed with $800 \mu \mathrm{L}$ of $95 \%$ EtOH and then with $600 \mu \mathrm{L}$ of $20 \% \mathrm{MeOH}+1 \% \mathrm{v} / \mathrm{v}$ glacial acetic acid with suction applied via a vacuum aspirator (Univac, Polyfiltronic). As soon as washing was complete, the extract was loaded under constant vacuum at a rate of $\approx 5 \mu \mathrm{L} \cdot \mathrm{s}^{-1}$. The column was then washed two times with $200 \mu \mathrm{L}$ of $20 \% \mathrm{MeOH}+1 \%$ v/v glacial acetic acid. Columns were then eluted with $200 \mu \mathrm{L}$ of $55 \% \mathrm{MeOH}$ and the ABA extract collected. Upon collection of elute, the samples were again stored at $-18^{\circ} \mathrm{C}$.

ABA Assay. ABA was assayed by enzyme linked immunosorbent assay (ELISA) as described by Alves and Setter (2000). Briefly, each well of a 96-well microtiter plate (Corning/Costar high binding \#3366) was coated with $20 \mu \mathrm{L}$ of ABA-bovine serum albumin conjugate. After incubation, for $24 \mathrm{~h}$ at $5^{\circ} \mathrm{C}$, the plate was decanted and washed four times with TBST (Tris buffered saline with $0.02 \% \mathrm{v} / \mathrm{v}$ Tween-20) with 5-minute incubations per wash. One hundred $\mu \mathrm{L}$ of TBSA (Tris buffered saline + bovine serum albumin) and $10 \mu \mathrm{L}$ of eluted sample were added to each well. Then $100 \mu \mathrm{L}$ of anti-ABA monoclonal antibody (clone $15-\mathrm{I}_{5}$, currently available from Agdia Inc., Elkhart, Ind.) was added to each well. The plate was incubated for $24 \mathrm{~h}$ at $5^{\circ} \mathrm{C}$. After incubation, the plate was again decanted and washed with TBST a total of four times. One hundred and eighty microliters of diluted secondary antibody (antimouse-alkaline phosphotase conjugate, Sigma product A-3562, in TBST with $0.1 \%$ [w/v] 
BSA) was added to each well. The plate was incubated at $5^{\circ} \mathrm{C}$ for $24 \mathrm{~h}$. Once the final incubation was complete, the plate was decanted and again washed four times. Colorimetric reagent, containing para-nitrophenylphosphate, PNPP (Sigma N3129) in diethanol-amine buffer was added and the plate was left to develop for $1 \mathrm{~h}$ at room temperature. After $1 \mathrm{~h}$, the plate was read with a plate reader at a wavelength of $405 \mathrm{~nm}$ (model 750; Cambridge Technology, Watertown, MA). (+)ABA content was determined by calculations based on $(+)$ ABA calibration standards. A spreadsheet macro written in Excel (Microsoft, Seattle, Wash.) provided a logit-transformed plot of the standard curve, calculated regressions, and predicted pmol ABA per well. Samples were replicated three times in the assay and averaged. Once the assay was complete, a $70-\mu \mathrm{L}$ aliquot was mixed with $400 \mu \mathrm{L}$ of scintillation fluid (Ecocint H; National Diagnostic, Manville, N.J.), and the radioactivity was measured in a scintillation counter (model LS 5000 TD; Beckman Inc., Fullerton, Calif.). Individual ABA samples were then corrected for loss that occurred in the chromatography clean up process.

DATA ANALYSIS. Gas exchange and ABA data were analyzed as a repeated measure using the GLM (General Linear Model) module (SPSS, Inc., 1999). To address the potential for between chamber variation in $\mathrm{A}_{\text {net }}, \mathrm{g}_{\mathrm{s}}$, and ABA a Fisher's least significant difference test $(P<0.01)$ was used to characterize the relationship between treatment chambers within a time interval. Paired $\mathrm{ABA}, \mathrm{A}_{\text {net }}$, and $\mathrm{g}_{\mathrm{s}}$ data were analyzed with a two level hierarchical model as covariates at the tree level (SAS proc mixed module; SAS Institute, Inc. 2000).

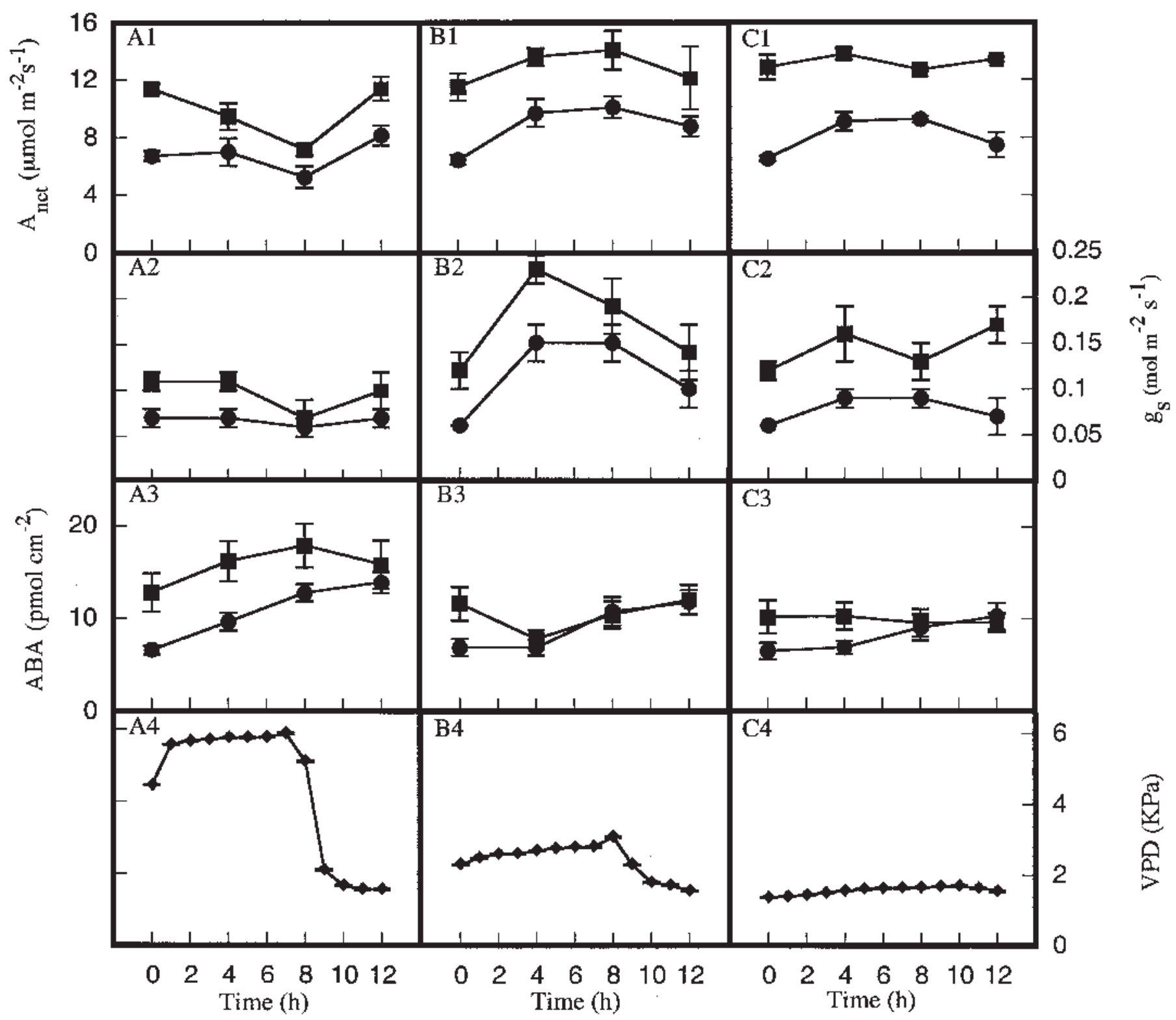

Fig. 1. Net photosynthesis $\left(\mathrm{A}_{\text {net }}\right)$, stomatal conductance to water vapor $\left(\mathrm{g}_{\mathrm{s}}\right)$, abscisic acid (ABA), and vapor pressure deficit of the atmospheric air $(\mathrm{VPD})(\bullet)$ of high VPD and air temperature maintained at $34{ }^{\circ} \mathrm{C}(\mathbf{A})$, moderate VPD and high air temperature maintained at $34{ }^{\circ} \mathrm{C}(\mathbf{B})$, and moderate VPD and air temperature maintained at $22^{\circ} \mathrm{C}(\mathbf{C})$. Photosynthetically active radiation (PAR) was provided by fluorescent lamps at a maximum photosynthetic photon flux of $375 \mu$ mol. $\mathrm{m}^{-2} \cdot \mathrm{s}^{-1}$ at the terminal tip of the canopy. Photoperiod was varied diurnally for a photoperiod of $14 \mathrm{~h}$ each day. The lamps were set to come on at $0600 \mathrm{HR}$ and shut off at 2000 HR. Data represent four consecutive times on wet-site (ם) and dry-site (-) seedlings of red maple. Each ABA point represents the mean of six replicate plants for each of four provenances per wet or dry site $\pm \mathrm{SE}$. As described in the methods section, data are a subset for gas exchange measurements. 


\section{Results}

Gas exchange and ABA relationship. The $\approx 5 \mathrm{kPa}$ VPD treatment resulted in increased leaf $\mathrm{ABA}$ over time, relative to control VPD levels of $\approx 1.2 \mathrm{kPa}(P<0.01)$ (Fig. 1). No treatment differences were observed at $0 \mathrm{~h}$ in any of the measured variables, however, significant differences were observed over time between treatments. In addition, $A_{\text {net }}, g_{\mathrm{s}}$, and ABA differed between wet versus dry sites in response to varied VPD $(P<0.01)$. Leaf gas exchange and ABA indicate the effect of atmospheric VPD demand and VPD relief (Fig. 1). Before the initiation of the treatments, wet-site ecotypes had a significantly higher leaf ABA level, $A_{\text {net }}$ rate, and $g_{\mathrm{s}}$ regardless of the treatment chamber $(P<0.01)$.

EFFECT OF HIGH VPD AND HIGH TEMPERATURE. Within the high VPD chamber, $A_{\text {net }}$ decreased $17 \%$ in the wet-site ecotype during the first $4 \mathrm{~h}$ of stress while dry-site plants remained unchanged (Fig. 1A1). Stomatal conductance remained relatively unchanged after the first $4 \mathrm{~h}$ of stress, whereas leaf ABA increased significantly (Fig. 1A2 and A3). The greatest change was observed between 4 to $8 \mathrm{~h}$, with a decrease of $36 \%$ and $15 \%$ in wet- and dry-site $g_{\mathrm{s}}$ respectively (Fig. 1A2). Photosynthesis reflected the decline in $g_{\mathrm{s}}$. However, wet- and dry-site declines in $A_{\text {net }}$ were similar during this period (Fig. 1A1). ABA accumulation, conversely, continued to increase between $4 \mathrm{~h}$ and $8 \mathrm{~h}$. Wet-site trees maintained higher leaf ABA but the rate of accumulation was similar for both ecotypes during the first $8 \mathrm{~h}$ (Fig. 1A3).

EFFECT OF MODERATE VPD AND HIGH TEMPERATURE. To elucidate temperature influence, samples were collected from plants grown in a chamber where VPD was maintained at moderate levels $(2.6 \pm 0.2 \mathrm{kPa})$. Within the high temperature and moderate VPD chamber, $A_{\text {net }}$ and $g_{\mathrm{s}}$ increased in both the wet- and dry-site ecotypes during 0 to $4 \mathrm{~h}$ (Fig. 1B1 and B2), while ABA levels either declined or remained constant. In dry-site trees, levels remained stable from hour 0 through 4 and then both ecotypes accumulated ABA similarly from hour 4 to 8 (Fig. 1 B3). Wet-site trees declined in ABA levels from 0 to $4 \mathrm{~h}$ with increases in $g$ s and $A_{\text {net }}$. After the initial increase, stomatal conductance and $A_{\text {net }}$ remained relatively unchanged between hours 4 to 8 , while an increase in leaf ABA levels occurred in both ecotypes (Fig. 1B3). In contrast to the VPD effects, elevated temperature resulted in a nearly opposite response with respect to $A_{\text {net }}$ and $g_{\mathrm{s}}$. Both ecotypes had elevated $A_{\text {net }}$ and $g_{\mathrm{s}}$ during the period when temperature was raised. Stomatal conductances in particular were about two times that of hour 0 when temperature was $22^{\circ} \mathrm{C}$ and VPD was $1.2 \pm$ $0.2 \mathrm{kPa}$. Once temperature was returned to ambient conditions (hour 8 to 12), $g_{\mathrm{s}}$ of trees in the $\mathrm{VPD}_{\mathrm{W}}$ chamber declined to near $0 \mathrm{~h}$ levels. In comparison, the ambient control chamber did not show a significant change in $A_{\text {net }}, g_{s}$, or ABA through 0 to 8 or 8 to $12 \mathrm{~h}$ at a VPD of $1.2 \pm 0.2 \mathrm{kPa}$. Regardless of ecotype, the stomatal conductance to water vapor and $A_{\text {net }}$ both increased during the poststress recovery period in the VPD chamber (Fig. 1A1 and A2). Moreover, hour 12 values of $A_{\text {net }}$ and $g_{\text {s }}$ were similar to hour 0 values for both ecotypes, with wet-site ecotypes persisting at higher $A_{\text {net }}$ and $g_{\mathrm{s}}$ levels throughout the time frame (Fig. $1 \mathrm{~A} 1$, and A2). $A_{\text {net }}$ and $g_{\mathrm{s}}$ declined in the $\mathrm{VPD}_{\mathrm{W}}$ and returned to prestress levels after $4 \mathrm{~h}$ of recovery.

EFFECT OF AMbient VPD AND AMBIENT TEMPERATURE. Within the VPD $\mathrm{A}_{\mathrm{A}}$ chamber, $A_{\text {net }}$ and $g_{\mathrm{s}}$ remained different between ecotypes with wet sites having both higher $A_{\text {net }}$ and $g_{\mathrm{s}}$ (Fig. 1C1 and $\mathrm{C} 2$ ). On the other hand, chamber effects through the entire time course were not significant on either ecotype. Moreover, ABA levels remained relatively unchanged (Fig. 1C3).
Stomatal ReSPonses. Figure 2 illustrates the sensitivity of $A_{\text {net }}$ and $g_{\mathrm{s}}$ to ABA accumulation and that $g_{\mathrm{s}}$ and $A_{\text {net }}$ decline more with ABA accumulation in wet, as opposed to dry sites. Additionally, Fig. 2 illustrates the mean of wet and dry sites across all conditions from hour 0 to 12 where linear regression indicates a significantly steeper slope for wet sites $(P<0.01)$. Wet-site ecotypes reduced $A_{\text {net }}$ and $g_{\text {s }}$ in association with increased levels of ABA. Wet-site ecotypes had higher levels of ABA and as ABA accumulated, $A_{\text {net }}$ and $g_{\mathrm{s}}$ declined, whereas dry sites did not decrease or increase $A_{\text {net }}$ and $g_{s}$ in association with ABA. Despite the fact that the rate of $\mathrm{ABA}$ accumulation in the wet-site plants was not significantly greater than the rate observed from the dry-site plants, significantly higher levels were still maintained in wet-site ecotypes. The steeper slope for wet sites illustrates the response to $\approx 5 \mathrm{pmol} \cdot \mathrm{cm}^{-2}$ of $\mathrm{ABA}$ accumulation, whereas the dry sites have less of a response with more ABA accumulation $\left(\approx 6 \mathrm{pmol} \cdot \mathrm{cm}^{-2}\right)$. Additionally, poststress $g_{\mathrm{s}}$ for wet-site ecotypes in the $\mathrm{VPD}_{\mathrm{W}}$ were similar to prestress, but dry sites remained elevated (0.01 versus 0.06 ). Lastly, poststress $A_{\text {net }}$ recovered to prestress rates across treatments with wet- and dry-site ecotypes behaving differently.

Figure 3 illustrates the relationship among physiological variables $A_{\text {net }}$ and $g_{s}$. The Loess method (Cleveland, 1979) was used for locally weighted scatter plot smoothing in Fig. 3 and weights

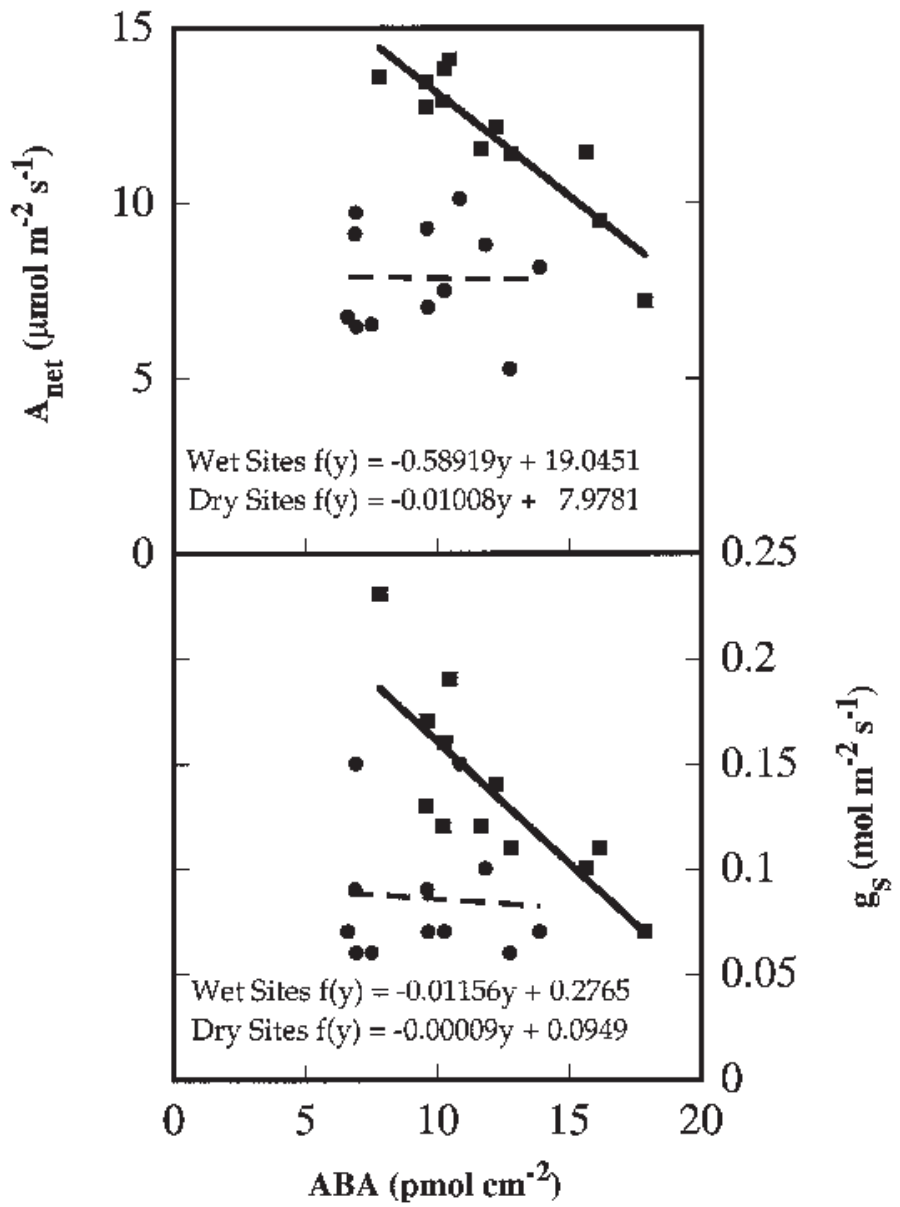

Fig. 2. The mean of wet and dry sites across all conditions from hour 0 to 12 Mean net photosynthesis $\left(\mathrm{A}_{\mathrm{net}}\right)$ and stomatal conductance to water vapor $\left(\mathrm{g}_{\mathrm{s}}\right)$ versus mean abscisic acid (ABA) concentration. Ecotypes are wet sites $(\mathbf{\square})$ and dry sites ( ). A linear regression was individually fit to both wet and dry sites with three iterations. Solid lines represent the linear regression curve for wet sites and broken lines represent dry sites. 


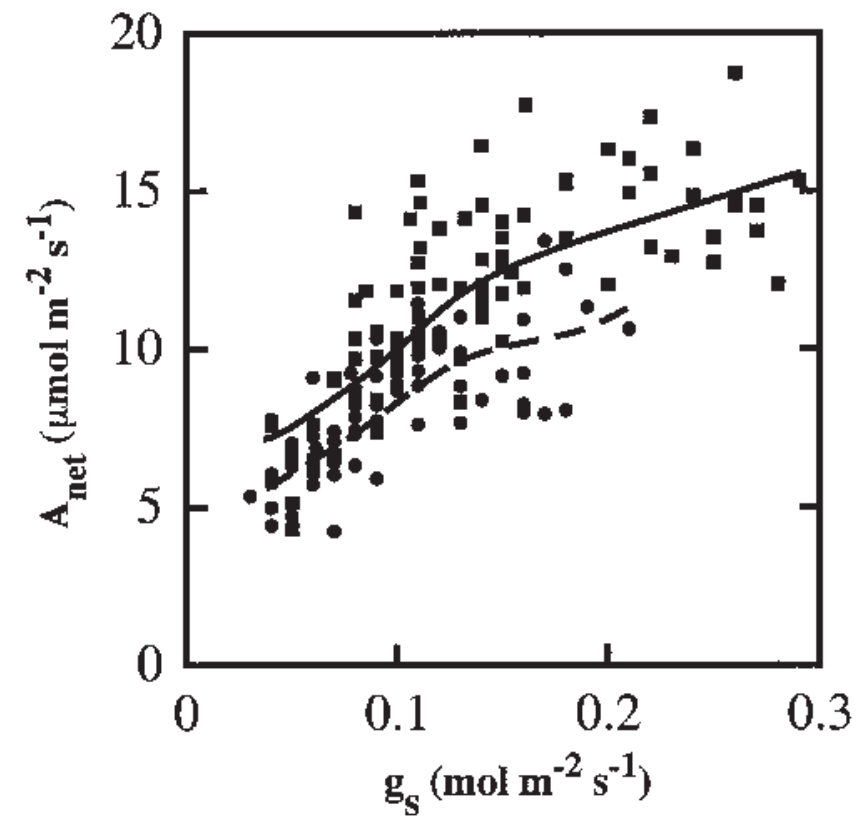

Fig. 3. Net photosynthesis $\left(A_{\text {net }}\right)$ and stomatal conductance to water vapor $\left(g_{s}\right)$. Ecotypes are wet sites $(\square)$ and dry sites $(\boldsymbol{O})$. A Loess curve was individually fit to both wet and dry sites with three iterations. Solid lines represent the Loess curve for wet sites and broken lines represent dry sites.

the proximate nearest neighboring points more heavily. Moreover, the Loess curve was fit to the data to compare the relationship between wet-site and dry-site $\mathrm{A}_{\text {net }}$ response to $\mathrm{g}_{\mathrm{s}}$. Wet-site plants had higher $A_{\text {net }}$ per unit $g_{\mathrm{s}}$ and wet-site $g_{\mathrm{s}}$ values extended beyond the maximum dry-site values.

\section{Discussion}

The results of high VPD conditions were compared to the effects of elevated temperature and ambient control conditions and are summarized as follows: 1) wet sites have more ABA than dry sites under similar initial and high VPD conditions; 2) both ecotypes appear to accumulate $\mathrm{ABA}$ at about the same rate when VPD is increased; 3 ) stomata of wet-site plants appear to be more sensitive, reducing both $A_{\text {net }}$ and $g_{\mathrm{s}}$ in response to ABA accumulation; and 4) dry-site plants do not seem to present as strong an $\mathrm{ABA} / g_{\mathrm{s}}$ relationship.

One mechanism by which red maple may regulate $g_{\mathrm{s}}$ and whole plant water loss is through ABA biosynthesis and catabolism. Previous studies have either documented or inferred the existence of 'non hydraulic' root signals in several woody species (Augé and Duan, 1991; Gowing et al., 1990; Fußeder et al., 1992; Khalil and Grace, 1993), including red maple (Augé et al., 2000; Croker et al., 1998). The identification of an underlying hormonal mechanism may explain stomatal responses and separate responses signaled by hydraulic and by nonhydraulic means.

Increasing levels of leaf ABA were associated with increased VPD. As the duration of the exposure to elevated VPD increased, both $A_{\text {net }}$ and $g_{\text {s }}$ declined from hours 4 to 8 . The levels of ABA in leaves exposed to high VPD was in some instances more than two fold the level at hour 0 (Fig. 1) and ABA levels began to decline after VPD was restored to ambient (hour 8 to 12), indicating that the stomatal response to VPD was reversible. Transpiration rates increased in the chamber where temperature was increased and VPD was maintained at moderate levels. The elevated transpiration rates in the temperature-elevated chamber do not support the possibility that guard cells sense water flux through the stomate. Moreover, the results reflect behavior under adequate soil moisture conditions, which diminished the probability that deficits were sensed by roots. Although the amount of ABA accumulation was different between ecotypes, the leaves of both ecotypes accumulated ABA apparently as a leaf-sensed response to atmospheric water deficits.

The literature reflects an ongoing controversy regarding the site of ABA synthesis. Abscisic acid in leaves and shoots could arise from leaf, root, or both (Hartung et al., 1998; Liang et al., 1997; Saliendra et al., 1995; Thompson et al., 1997). Regardless of the site of synthesis, ABA concentrations in both the leaf and shoot xylem has often been correlated with $g_{\text {s }}$ rather than leaf $\Psi$ or soil $\Psi$ (Augé et al., 2000). Wet-site plants reduced $A_{\text {net }}$ and $g_{\mathrm{s}}$ with increasing ABA concentrations, whereas there was no relationship for the dry-site ecotype. Abscisic acid is likely to regulate stomatal aperture during periods of high VPD or low soil $\Psi$ in red maple from wet sites to a greater degree than trees from dry sites. The hypothesis that ABA is the only root signaling molecule, however, has been challenged (Munns, 1992; Munns and King, 1988;Munns et al., 1993; Trejo and Davies 1991). There is a paucity of studies that investigate the effect of soil versus atmospheric water deficit on the production of ABA. Gollan et al. (1986) and Turner et al. (1985) carefully unscrambled the effect of VPD and soil drying on photosynthesis and conductance that led to the subsequent work on root-shoot signals and ABA. Augé et al. (2000) found that VPD better described stomata sensitivity to ABA than shoot water potential $\left(\Psi_{w}\right)$. Nonetheless, a nonhydraulic chemical factor that permits plants to sense and respond to soil drying seems to exist (Davies and Zhang, 1991; Davies et al., 1994; Liang et al., 1996; Loewenstein and Pallardy, 1998a, 1998b; Zhang et al., 1987).

Variation in sensitivity of $g_{s}$ to VPD has been observed at both the intra- and interspecific levels (e.g., Aphalo and Jarvis, 1991, Yong et al., 1997). Sensitivity generally increases and is linked with a higher $g_{\mathrm{s}}$ at low VPD (Kaufmann, 1982; McNaughton and Jarvis, 1991; Yong et al., 1997). Contrary to the stomatal response to humidity studied by Assmann et al. (2000) in Arabidopsis, the analysis of the ambient and elevated temperature treatments indicated almost no depression of photosynthesis, confirming that the artificially elevated VPD initiated the humidity response.

Red maple ecotypes have evolved to either lower the capacity for growth (dry sites) or increase stomatal sensitivity (wet sites) to limit water loss. Wet site ecotypes might be expected to respond quicker and to a greater extent than dry sites by biosynthesizing ABA, temporarily reducing $g_{\mathrm{s}}$, and thereby avoiding plant water stress. Dry-site ecotypes continued to accumulate ABA even after the stress was relieved, indicating low sensitivity to changes in VPD. Wet-site ecotypes were more sensitive to VPD as indicated by greater reductions in both $g_{\mathrm{s}}$ and $A_{\text {net. }}$. This suggests that stomatal sensitivity to a nonhydraulic signal is not only a distinguishing character between species with different tolerance for water deficits (Croker et al., 1998), but also discriminates among ecotypes within a species. This trend in red maple ecotypes is consistent with the theory of Oren et al. (1999) where higher $g_{\text {s }}$ at low VPD exhibits a proportionally more sensitive stomatal closure with increasing VPD.

The hydrologic differences between the sites from which the wet- and dry-site ecotypes originate vary in relation to soil water availability, in that wet sites have perennially saturated soil while dry-site soils are shallow, coarse and excessively well drained. The current study indicates that there is considerable 
ABA accumulation that is linked to the VPD environment in the canopy (Fig. 1A3). The sustained high VPD could have increased synthesis of ABA in the leaf, as evidenced by increases in bulk leaf ABA. In addition, leaf-sourced changes in $\mathrm{pH}$ could also have occurred in response to high VPD (Wilkinson and Davies, 2002). The wet-site ecotype guard cell sensitivity to a pH (and ABA) change over the course of the high VPD exposure may have caused the difference in response between ecotypes. Changes in guard cell sensitivity to ABA often occur in response to changes in electrical and osmotic membrane potentials generated by the guard cells (Assmann and Shimazaki, 1999; Blatt, 2000). Like responses to soil water deficit, responses to VPD may differ between ecotypes. This research demonstrates that ecotypes of red maple may be selected for atmospheric drought tolerance based on site moisture conditions. More fundamental research is needed to further elucidate the linkage between atmospheric stress and $\mathrm{ABA} \mathrm{g}_{\mathrm{s}}$ control and the genetics underlying hormonal variation within a species.

\section{Literature Cited}

Abrams, M.D. and M.E. Kubiske. 1990. Photosynthesis and water relations during drought in Acer rubrum L. genotypes from contrasting sites in central Pennsylvania. Funct. Ecol. 4:727-733.

Alves, A.C. and T.L. Setter. 2000. Response of Cassava to water deficit: Leaf area growth and abscisic acid. Crop Sci. 40(1):131-137.

Aphalo, P.J. and P.G. Jarvis. 1991. Do stomata respond to relative humidity? Plant Cell Environ. 14:127-132.

Assmann, S.M. and K.-L. Shimazaki. 1999. The multisensory guard cell, stomatal responses to blue light and abscisic acid. Plant Physiol. 119:809-816.

Assmann, S.M., J.O. Snyder, and Y-R.J. Lee. 2000. ABA-deficient (aba1) and ABA-insensitive (abi1-1, abi2-1) mutants of Arabidopsis have a wild-type stomatal response to humidity. Plant Cell Environ. 23:387-395.

Augé, R.M., C.D. Green, A.J.W. Stodola, A.M. Saxton, J.B. Olinick, and R.M. Evans. 2000. Correlations of stomatal conductance with hydraulic and chemical factors in several deciduous tree species in a natural habitat. New Phytol. 145:483-500.

Augé, R.M. and X. Duan. 1991. Mycorrhizal symbiosis and nonhydraulic root signals of drying soil. Plant Physiol. 97:821-824.

Bauerle, W.L., J.B. Dudley, and L.W. Grimes. 2003a. Genotypic variability in photosynthesis, water use, and light absorption among red and Freeman maple cultivars in response to drought stress. J. Amer. Soc. Hort. Sci. 128:337-342.

Bauerle, W.L., T. H. Whitlow, T.L. Setter, T.L. Bauerle,and F.M. Vermeylen. 2003b. Ecophysiology of Acer rubrum L. seedlings from contrasting hydrologic habitats: growth, gas exchange, tissue water relations, abscisic acid, and carbon isotope discrimination. Tree Physiol. 23:841-850.

Blatt, M.R. 2000. Cellular signalling and volume control in stomatal movements in plants. Annu. Rev. Cell. Dev. Biol. 16:221-241.

Cleveland, W.S. 1979. Robust locally weighted regression and smoothing scatterplots. J. Amer. Stat. Assoc. 74:829-836.

Croker, J.L., W.T. Witte, and R.M. Augé. 1998. Stomatal sensitivity of six temperate, deciduous tree species to nonhydraulic root-to-shoot signalling of partial soil drying. J. Expt. Bot. 49(321):761-774.

Davies, W.J. and J. Zhang. 1991. Root signals and the regulation of growth and development of plants in drying soil. Annu. Rev. Plant Physiol. Plant Mol. Biol. 42:55-76.

Davies, W.J., F. Tardieu, C.L. Trejo, and H.G. Jones. 1994. How do chemical signals work in plants that grow in drying soil? Plant Physiol. 104:309-314.

Fußeder, A., A. Wartinger, W. Hartung, E.D. Schulze, and H. Heilmeier. 1992. Cytokinins in the xylem sap of desert-grown almond (Prunus dulcis) trees: Daily courses and their possible interactions with abscisic acid and leaf conductance. New Phytol. 122:45-52.

Fuchs, E.E. and N.J. Livingston. 1996. Hydraulic control of stomatal conductance in douglas fir (Pseudotsuga menziesii (Mirb.) Franco) and alder (Alnus rubra (Bong)) seedlings. Plant Cell Environ. 19:1091-1098.

Gollan, T., J.B. Passioura, and R. Munns. 1986. Soil water status affects stomatal conductance of fully turgid wheat and sunflower leaves. Austral. J. Plant Physiol. 13:459-464.

Gowing, D.J.G., W.J. Davies, and H.G. Jones. 1990. A positive root-sourced signal as an indicator of soil drying in apple, Malus $\times$ domestica Borkh. J. Expt. Bot. 41:1535-1540.
Hartung, W., S. Wilkinson, and W.J. Davies. 1998. Factors that regulate abscisic acid concentrations at the primary site of action at the guard cell. J. Expt. Bot. 49:361-367.

Kaufmann, M.R. 1982. Leaf conductance as a function of photosynthetic photon flux density and absolute humidity difference from leaf to air. Plant Physiol. 69:1018-1022.

Khalil, A.A.M. and J. Grace. 1993. Does xylem sap ABA control the stomatal behavior of water-stressed sycamore (Acer pseudoplatunus L.) seedlings? J. Expt. Bot. 44:1127-1134.

Liang, J., J. Zhang, and M. Wong. 1996. Stomatal conductance in relation to xylem ABA concentration in two tropical trees, Acacia confusa and Litsea glutinosa. Plant Cell Environ. 19:93-100.

Liang, J., J. Zhang, and M. Wong. 1997. How do roots control xylem sap ABA concentration in response to soil drying? Plant Cell Environ. 38:10-16.

Loewenstein, N.J. and S.G. Pallardy. 1998a. Drought tolerance, xylem sap abscisic acid and stomatal conductance during soil drying: A comparison of young plants of four temperate deciduous angiosperms. Tree Physiol. 18:421-430.

Loewenstein, N.J. and S.G. Pallardy. 1998b. Drought tolerance, xylem sap abscisic acid and stomatal conductance during soil drying: A comparison of canopy trees of three temperate deciduous angiosperms. Tree Physiol. 18:431-439.

Maroco, J.P., J.S. Pereira, and M.M. Chaves. 1997. Stomatal responses to leafto-air vapour pressure deficit in sahelian species. Austral. J. Plant Physiol. 24: 381-387.

McNaughton, K.G. and P.J. Jarvis. 1991. Effects of spatial scale on stomatal control of transpiration. Agr. For. Meteorol. 54:279-301.

Meinzer, F.C., J.L. Andrade, G. Goldstein, N.M. Holbrook, J. Cavelair, and P. Jackson. 1997. Control of transpiration from the upper canopy of a tropical forest: The role of stomatal, boundary layer and hydraulic architecture components. Plant Cell Environ. 20:1242-1252.

Monteith, J.L. 1995. A reinterpretation of stomatal responses to humidity. Plant Cell Environ. 18:357-364.

Munns, R. 1992. A leaf elongation bioassay detects an unknown growth inhibitor in xylem sap from wheat and barley. Austral. J. Plant Physiol. 19:127-135.

Munns, R. and R.W. King. 1988. Abscisic acid is not the only stomatal inhibitor in the transpiration stream of wheat plants. Plant Physiol. 88:703-708.

Munns, R., J.B. Passioura, B.V. Milborrow, R.A. James, and T.J. Close. 1993. Stored xylem sap from wheat and barley in drying soil contains a transpiration inhibitor with a large molecular size. Plant Cell Environ. 16:867-872.

Oren, R., J.S. Sperry, G.G. Katul, B.E. Ewers, D.E. Pataki, N. Phillips, and K.V.R. Schafer. 1999. Survey and synthesis of intra-and inter-specific responses of canopy stomatal conductance to vapor pressure deficit. Plant Cell Environ. 22:1515-1526.

Saliendra, N.Z., J.S. Sperry, and J.P. Comstock. 1995. Influence of leaf water status on stomatal response to humidity, hydraulic conductance, and soil drought in Betula occidentalis. Planta 196(2):357-366.

SAS Institute, Inc. 1989. SAS user's guide. Statistics. $6^{\text {th }}$ ed. SAS Inst., Inc. Cary, N.C.

Sheriff, D.W. 1979. Stomatal aperature and the sensing of the environment by guard cells. Plant Cell Environ. 2:15-22.

SPSS Inc. 1999. SPSS version 9.0. SPSS Inc. Chicago, Ill.

Thomas, D.S. and D. Eamus. 1999. The influence of predawn leaf water potential on stomatal responses to atmospheric water content at constant $C_{i}$ and on stem hydraulic conductance and foliar ABA concentrations. J. Expt. Bot. 50(331): 243-251.

Thompson, D.S., S. Wilkinson, M.A. Bacon, and W.J. Davies. 1997. Multiple signals and mechanisms that regulate leaf growth and stomatal behavior during water deficits. Physiol. Plant. 100:303-313.

Townsend, A.M. and B.R. Roberts. 1973. Effect of moisture stress on red maple seedlings from different seed sources. Can. J. Bot. 51:1989-1995.

Trejo, C.L. and W.J. Davies. 1991. Drought-induced closure of Phaseolus vulgaris L. stomata precedes leaf water deficit and any increase in xylem ABA concentration. J. Exp. Bot. 42(245):1507-1515.

Turner, N.C., E.D. Schulze, and T. Gollan. 1985. The response of stomata and leaf gas exchange to vapour pressure deficits and soil water content. II. In the mesophytic herbaceous species Heliantus annus. Oecologia 65:348-355.

Walters, R.S. and H.W. Yawney. 1990. Acer rubrum L., rep maple. In Silvics of North America. Agricultural Handbook, II Hardwoods(654).

Wilkinson, S. and W.J. Davies. 2002. ABA-based chemical signalling: the coordination of responses to stress in plants. Plant Cell Environ. 25:195-210.

Yong, J.W.H., S.C. Wong, and G.D. Farquhar. 1997. Stomatal response to changes in vapour pressure difference between leaf and air. Plant Cell Environ. 20: 1213-1216.

Zhang, J.,U. Schurr, and W.J. Davies. 1987. Control of stomatal behavior by abscisic acid which apparently originates in the roots. J. Expt. Bot. 38:1174-1181. 